\title{
TU/e EmonOWEN

\section{Substrate biasing during plasma-assisted ALD for crystalline phase-control of TiO2 thin films}

\section{Citation for published version (APA):}

Profijt, H. B., Sanden, van de, M. C. M., \& Kessels, W. M. M. (2012). Substrate biasing during plasma-assisted ALD for crystalline phase-control of TiO2 thin films. Electrochemical and Solid-State Letters, 15(2), G1-G3. https://doi.org/10.1149/2.024202es|

DOI:

10.1149/2.024202esl

Document status and date:

Published: 01/01/2012

\section{Document Version:}

Publisher's PDF, also known as Version of Record (includes final page, issue and volume numbers)

\section{Please check the document version of this publication:}

- A submitted manuscript is the version of the article upon submission and before peer-review. There can be important differences between the submitted version and the official published version of record. People interested in the research are advised to contact the author for the final version of the publication, or visit the $\mathrm{DOI}$ to the publisher's website.

- The final author version and the galley proof are versions of the publication after peer review.

- The final published version features the final layout of the paper including the volume, issue and page numbers.

Link to publication

\section{General rights}

Copyright and moral rights for the publications made accessible in the public portal are retained by the authors and/or other copyright owners and it is a condition of accessing publications that users recognise and abide by the legal requirements associated with these rights.

- Users may download and print one copy of any publication from the public portal for the purpose of private study or research.

- You may not further distribute the material or use it for any profit-making activity or commercial gain

- You may freely distribute the URL identifying the publication in the public portal.

If the publication is distributed under the terms of Article 25fa of the Dutch Copyright Act, indicated by the "Taverne" license above, please follow below link for the End User Agreement:

www.tue.nl/taverne

Take down policy

If you believe that this document breaches copyright please contact us at:

openaccess@tue.nl

providing details and we will investigate your claim. 


\title{
Substrate Biasing during Plasma-Assisted ALD for Crystalline Phase-Control of $\mathrm{TiO}_{2}$ Thin Films
}

\author{
H. B. Profijt, ${ }^{*}$ M. C. M. van de Sanden, and W. M. M. Kessels ${ }^{* *, z}$
}

Department of Applied Physics, Eindhoven University of Technology, 5600 MB Eindhoven, The Netherlands

\begin{abstract}
Substrate biasing has been implemented in a remote plasma atomic layer deposition (ALD) reactor, enabling control of the ion energy up to $260 \mathrm{eV}$. For $\mathrm{TiO}_{2}$ films deposited from $\mathrm{Ti}\left(\mathrm{Cp}^{\mathrm{Me}}\right)\left(\mathrm{NMe}_{2}\right)_{3}$ and $\mathrm{O}_{2}$ plasma it is demonstrated that the crystalline phase can be tailored by tuning the ion energy. Rutile $\mathrm{TiO}_{2}$ was obtained at 200 and $300^{\circ} \mathrm{C}$, typically yielding amorphous and anatase films without biasing. Aspects such as film mass density, [O]/[Ti] ratio and growth per cycle under biased conditions are addressed. The results demonstrate that substrate biasing is a viable method for ALD to tailor ultra-thin film properties.

(C) 2011 The Electrochemical Society. [DOI: 10.1149/2.024202esl] All rights reserved.
\end{abstract}

Manuscript submitted October 12, 2011; revised manuscript received November 10, 2011. Published December 14, 2011.

For certain thin film materials and applications, plasma-assisted atomic layer deposition (ALD) can offer an increased level of freedom in material properties and processing conditions compared to thermal ALD. ${ }^{1}$ This freedom can be attributed to the presence of reactive radicals and ions which interact with the material surface during deposition. The use of a plasma furthermore offers an increased number of process parameters that can be varied to influence the properties of the thin films deposited. A parameter that has, however, not yet been explored for plasma-assisted ALD is the substrate potential which directly affects the ion energy. ${ }^{2}$ In electropositive processing plasmas, the average potential of the plasma is positive with respect to the grounded reactor walls and substrate stage. As a result, positive ions are accelerated in a thin space charge layer, the plasma sheath, towards the grounded reactor walls and the substrate stage. For the case of a collisionless plasma sheath (i.e. at relatively low pressures), the kinetic energy of the ions $E_{\mathrm{i}}$ can be expressed by $E_{\mathrm{i}}=e\left(V_{\mathrm{p}}-V_{\mathrm{s}}\right)$, where $V_{\mathrm{p}}$ is the plasma potential and $V_{\mathrm{s}}$ is the substrate potential. This expression illustrates that the energy with which the ions arrive at the substrate surface is increased for a more negatively biased substrate stage. Recently, we illustrated that during remote plasma ALD under regular conditions (i.e. with a grounded substrate stage) the ion energy can be sufficiently high to play a role during the ALD process, e.g. by enhancing adatom migration and ligand removal. ${ }^{3}$ With substrate biasing even higher ion energies can be reached and an increased number of physical surface reactions can be expected to play a role during ALD. 4

For plasma-enhanced chemical vapor deposition (PECVD), substrate biasing has already proven its value in tailoring thin film material properties. For the deposition process of $\mathrm{Si}$, for example, the microstructure, density and crystallinity can be affected by controlling the substrate bias voltage. ${ }^{5,6}$ For PECVD of $\mathrm{TiO}_{2}$ the effect of substrate biasing has been confirmed as well - the deposition rate and the crystalline phase are affected by a bias voltage applied to the substrate stage. ${ }^{7-9}$ Also for $\mathrm{ZnO}$, the influence of RF substrate biasing was demonstrated and the preferred orientation, the crystal size, and the thermal stability of the films were shown to be affected by the bias power. ${ }^{10}$ Being a different deposition method ruled by surface chemistry, it is also interesting to study the influence of substrate biasing for the case of plasma-assisted ALD.

In this letter, we demonstrate that substrate biasing is a viable technique during plasma-assisted ALD to tailor material properties of ultra-thin films. More specifically, it is shown that substrate biasing allows for control over the phase composition of $\mathrm{TiO}_{2}$ thin films deposited at relatively low substrate temperatures. It is also revealed that substrate biasing affects the mass density, the [O]/[Ti] ratio and the growth per cycle (GPC).

\footnotetext{
* Electrochemical Society Student Member.

** Electrochemical Society Active Member.

${ }^{z}$ E-mail: w.m.m.kessels@tue.nl
}

The experiments were carried out in a remote plasma ALD reactor equipped with an inductively-coupled plasma (ICP) source. The reactor is schematically illustrated in Fig. 1. During the plasma step of the ALD cycle, the substrate stage was electrically grounded or biased by substrate-tuned biasing ${ }^{11}$ or RF biasing. ${ }^{2}$ With substrate-tuned biasing, only a matching network was connected to the substrate stage (4 inch diameter) and the bias voltage was controlled by adjusting the impedance between the substrate stage and the ground potential. ${ }^{11}$ In the case of RF biasing, a power supply (denoted by the asterisk in Fig. 1) was connected to the matching network. The substrate can be grounded by closing a switch that electrically connects the substrate stage and the grounded reactor wall. Films were deposited on $1 \times 1$ inch substrates, cut from a $n$-type c-Si (100) wafer with a resistivity of $0.004-0.007 \Omega \cdot \mathrm{cm}$. During $\mathrm{TiO}_{2}$ deposition, the substrate was alternately exposed to $\mathrm{Ti}\left(\mathrm{Cp}^{\mathrm{Me}}\right)\left(\mathrm{NMe}_{2}\right)_{3}$ (SAFC Hitech Ltd.) and a $200 \mathrm{~W} \mathrm{O}_{2}$ plasma with dosing times of 5 and $10 \mathrm{~s}$, respectively, separated by $5 \mathrm{~s}$ purge steps. The chamber was continuously purged by $\mathrm{O}_{2}$ at $7.5 \mathrm{mTorr}$ provided through the ICP source, which was possible since no reaction between $\mathrm{O}_{2}$ and the precursor was observed under the conditions employed. Films were deposited at 100, 200, and $300^{\circ} \mathrm{C}$. Substrate-tuned biasing was utilized to achieve bias voltages of -50 and $-100 \mathrm{~V}$ and RF biasing was used for $-100,-150$ and $-200 \mathrm{~V}$. A retarding field energy analyzer (RFEA) was employed to determine the ion energy distribution function (IEDF) for the $\mathrm{O}_{2}$ plasma. ${ }^{2,12}$

Figure 2 displays the IEDFs measured for substrate-tuned bias voltages between 0 and $-100 \mathrm{~V}$. The inset of this figure shows the average ion energy deduced from the IEDFs. For the case of a grounded substrate stage (i.e. with the switch closed), the ion energy is monomodally distributed and peaks at $33 \pm 1 \mathrm{eV}$. The value for the ion energy is somewhat higher than reported earlier for an $\mathrm{O}_{2}$ plasma in the Oxford Instruments FlexAL reactor. ${ }^{3}$ In that case the plasma was operated at a higher gas pressure and in a reactor with a different geometry, both reducing the ion energy. When the substrate stage is biased, the ion energy distribution becomes bi-modal. This is a result of the fact that the ion transit time (i.e. the time it takes for an ion to travel through the plasma sheath) is lower than the RF cycle time (being $73.7 \mathrm{~ns}$ ) of the plasma source. Consequently, ions that pass the plasma sheath at different time instances within one RF cycle obtain different energies since the sheath voltage drop is different. For a detailed explanation on the origin of the bimodal distribution, the reader is referred to Edelberg et al. ${ }^{2}$

In the case the substrate is biased at $-100 \mathrm{~V}$, the ion energy is distributed between 121 and $155 \pm 1 \mathrm{eV}$ and the average value is $138 \pm 1 \mathrm{eV}$. Since the pressure is relatively low, the plasma sheath is collisionless, which is confirmed by the absence of low-energy tails in the ion energy distributions. When the power supply is connected to the matching network, a power of $4 \mathrm{~W}$ is needed to bias the substrate at $-100 \mathrm{~V}$. The bias voltage can be further increased to -150 and $-200 \mathrm{~V}$ by setting the power to 14 and $24 \mathrm{~W}$, respectively. For these biasing conditions, average ion energies of 197 and $260 \pm 1 \mathrm{eV}$ were 


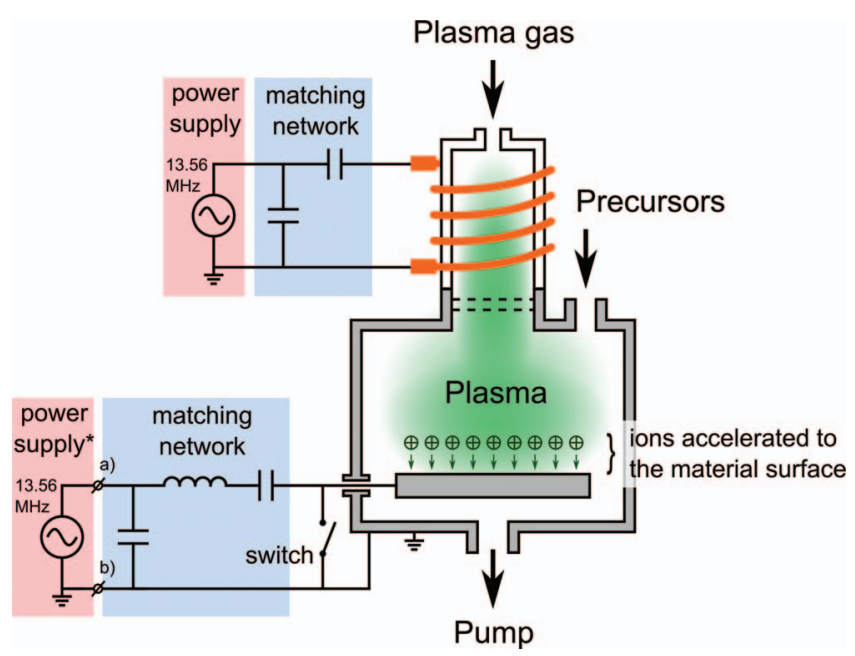

Figure 1. Remote plasma ALD reactor equipped with an inductively coupled plasma source. A matching network is connected to the substrate stage to control the substrate potential by substrate-tuned biasing. The asterisk denotes the power supply that is additionally connected (at nodes "a)" and "b)") to the matching network in the case of RF biasing. The substrate stage also can be directly connected to the grounded reactor wall by closing the switch.

found by extrapolating the average ion energies obtained for substratetuned biasing. Planar probe measurements confirmed that the ion flux to the substrate surface is hardly affected by substrate-tuned biasing and is in the order of $10^{14} \mathrm{~cm}^{-2} \mathrm{~s}^{-1}$.

Grazing-incidence X-ray diffraction measurements (XRD) were carried out on $\sim 30 \mathrm{~nm}\left(200^{\circ} \mathrm{C}\right.$ series $)$ and $\sim 50 \mathrm{~nm}\left(300^{\circ} \mathrm{C}\right.$ series $)$ thick $\mathrm{TiO}_{2}$ films and the spectra are shown in Fig. 3. For films deposited at $300^{\circ} \mathrm{C}$ and a substrate potential of $0 \mathrm{~V}$, the XRD spectrum includes the (101), (004), (200), (105), and (211) diffraction peaks corresponding to the anatase $\mathrm{TiO}_{2}$ phase. When a bias voltage of $-50 \mathrm{~V}$ is applied, the magnitude of these peaks decreases, while the (110) peak related to the rutile $\mathrm{TiO}_{2}$ phase starts appearing. When the bias voltage is further increased, the anatase diffraction peaks gradually disappear and the (110), (101), (111), and (211) diffraction peaks, corresponding to the rutile phase, increase in magnitude. At $-200 \mathrm{~V}$ solely peaks related to the rutile phase are visible in the spectrum. A difference can be observed between the spectra for $-100 \mathrm{~V}$ substrate-tuned biasing and $-100 \mathrm{~V}$ RF-biasing. This difference is expected to originate from a

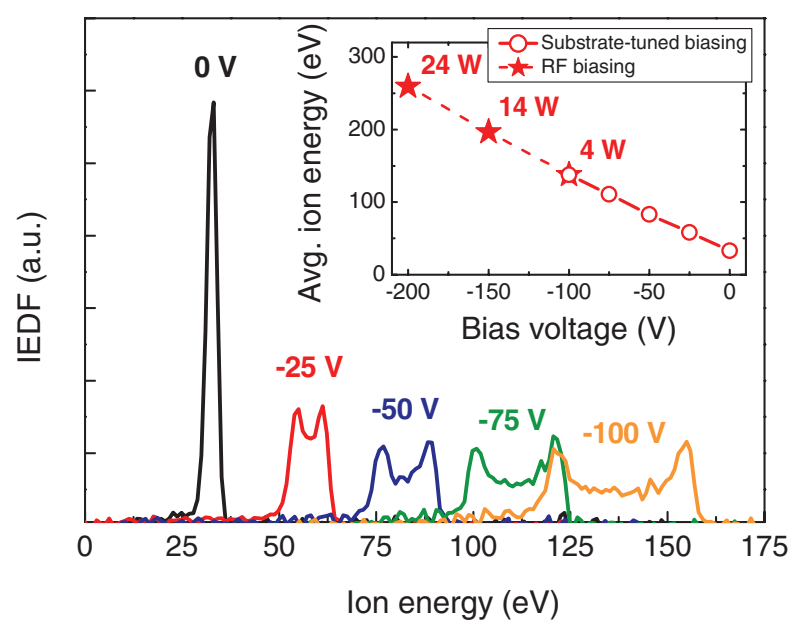

Figure 2. Ion energy distribution functions (IEDFs) for bias voltages of 0 to $-100 \mathrm{~V}$, obtained by substrate-tuned biasing. The inset shows the average ion energy as a function of the bias voltage. For substrate-tuned biasing, the average ion energies are derived from the IEDFs, whereas the values for RF biasing are extrapolated values.

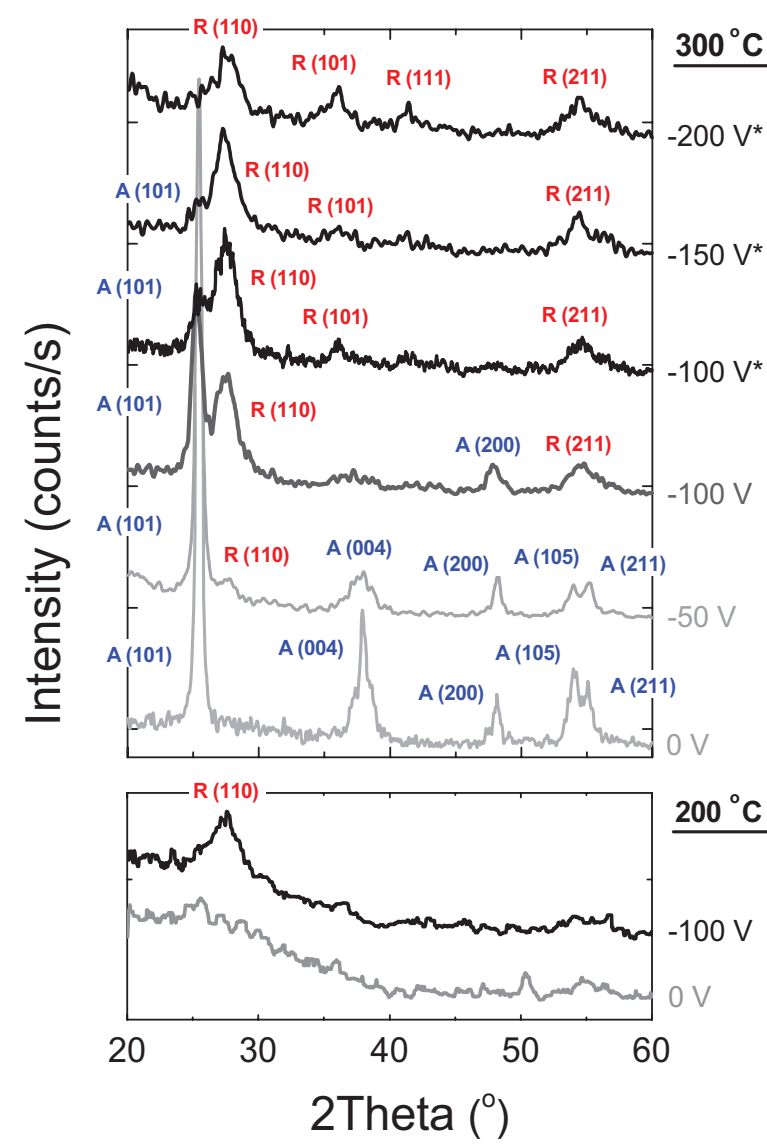

Figure 3. X-ray diffraction spectra for $\mathrm{TiO}_{2}$ films deposited at 200 and $300^{\circ} \mathrm{C}$ for different bias voltages. Peaks corresponding to the anatase and rutile crystalline phases are denoted with "A" and "R", respectively. Substrate-tuned biasing was employed for -50 and $-100 \mathrm{~V}$, whereas RF substrate biasing was applied for $-100,-150$ and $-200 \mathrm{~V}$ (labeled by asterisks).

change in the plasma density and electron temperature as a result of the increase in power delivered to the plasma with $\mathrm{RF}$ biasing. $\mathrm{TiO}_{2}$ films deposited at $200^{\circ} \mathrm{C}$ are amorphous, however when $-100 \mathrm{~V}$ biasing is applied the (110) rutile phase peak appears in the XRD spectrum. Films deposited at $100^{\circ} \mathrm{C}$ remain amorphous even when substrate biasing is applied (not shown). It is noted that we verified that substrate biasing does not significantly heat the samples, by monitoring the substrate temperature using a thermocouple connected to the substrate stage.

The impact of substrate biasing was furthermore evaluated by Rutherford backscattering spectroscopy (RBS), elastic recoil detection (ERD), and X-ray photoelectron spectroscopy (XPS). Table I shows that films deposited without substrate biasing are stoichiometric, have a mass density typical for ALD-prepared $\mathrm{TiO}_{2}$ films and contain $<2$ at. $\% \mathrm{H}$. The film properties for $\mathrm{TiO}_{2}$ deposited at a bias voltage of $-50 \mathrm{~V}$ are very similar, however $\mathrm{TiO}_{2}$ films deposited at higher bias voltages show a pronounced change in the compositional material properties. The $[\mathrm{O}] /[\mathrm{Ti}]$ ratio increases and the mass density decreases with increasing bias voltage. From in-depth analysis of the ERD results, the knowledge is gained that for bias voltages of 0 and $-50 \mathrm{~V}$ the 1.4 at. $\% \mathrm{H}$ in the films is mainly present at the $\mathrm{TiO}_{2}$ surface as well as at the $\mathrm{TiO}_{2}$ interface with the substrate. For films deposited at higher bias voltages a considerable amount of $\mathrm{H}$ seems to be present in the bulk, particularly as -OH groups, as confirmed by X-ray photoelectron spectroscopy (XPS) measurements. These OH groups are apparently more incorporated under biased conditions and are the reason for lower density films obtained for higher bias voltages. Using ex-situ spectroscopic ellipsometry (SE) the average GPC for the $\mathrm{TiO}_{2}$ 
Table I. Influence of the bias voltage on the material properties of $\sim 50 \mathrm{~nm}$ thick $\mathrm{TiO}_{2}$ films deposited at $300^{\circ} \mathrm{C}$. Substrate-tuned biasing was employed for -50 and $-100 \mathrm{~V}$, whereas RF substrate biasing was applied for $-\mathbf{1 0 0},-150$ and $-200 \mathrm{~V}$ (voltages labeled by asterisks). The relative errors in the $[\mathrm{O}] /[\mathrm{Ti}]$ ratio, the mass density and the number of $\mathrm{Ti}$ atoms deposited (all determined by $\mathrm{RBS}$ ) are $4 \%, 4 \%$ and $3 \%$, respectively. For the $\mathrm{H}$ content (determined by ERD), the relative error is $7 \%$.

\begin{tabular}{ccccc}
$\begin{array}{c}\text { Bias voltage } \\
(\mathrm{V})\end{array}$ & $\begin{array}{c}{[\mathrm{O}] /[\mathrm{Ti}]} \\
\text { ratio }\end{array}$ & $\begin{array}{c}\text { Mass density } \\
\left(\mathrm{g} \mathrm{cm}^{-3}\right)\end{array}$ & $\begin{array}{c}\mathrm{H} \text { content } \\
(\text { at.\% })\end{array}$ & $\begin{array}{c}\text { Ti atoms deposited } \\
\left(\times 10^{14} \mathrm{~cm}^{-2} \mathrm{cycle}^{-1}\right)\end{array}$ \\
\hline 0 & 2.0 & 3.7 & 1.4 & 2.4 \\
-50 & 2.0 & 3.7 & 1.4 & 2.6 \\
-100 & 2.2 & 3.4 & 5.2 & 2.3 \\
$-100^{*}$ & 2.3 & 3.5 & 4.4 & 2.2 \\
$-150^{*}$ & 2.3 & 3.3 & 4.0 & 2.3 \\
$-200^{*}$ & 2.4 & 3.3 & 6.1 & 2.2
\end{tabular}

films was determined to be $0.86 \AA$ /cycle without biasing, and 0.89 and $0.94 \AA /$ cycle for a $-100 \mathrm{~V}$ and $-200 \mathrm{~V}$ RF biased substrate stage, respectively. The growth in terms of $\mathrm{Ti}$ atoms per cycle is approximately constant over the range of bias voltages applied (see Table I) and therefore the increased GPC can be attributed to the lower density of the films under these conditions. The $\mathrm{N}$ and $\mathrm{C}$ impurity levels (determined by XPS, not shown in table) are respectively 0.1 and 0.5 at.\% for films deposited without biasing, comparable to $\mathrm{TiO}_{2}$ films previously deposited using the same precursor. ${ }^{13}$ When $-200 \mathrm{~V}$ RF biasing is applied, the $\mathrm{N}$ and $\mathrm{C}$ contents increased to 0.8 and 1.0 at.\%. These higher impurity levels are expected to originate from precursor ligands decomposed by the impact of high energy ions.

This study demonstrates that substrate biasing allows for additional control over thin film material properties during plasma-assisted ALD, by tuning the ion energy. More specifically, it shows that the phase composition of $\mathrm{TiO}_{2}$ thin films can be tailored by substrate biasing, in addition to other parameters reported in the literature such as the reactant pressure, the deposition temperature, the substrate material and post-deposition annealing. ${ }^{13-15}$ Also the compositional properties of the $\mathrm{TiO}_{2}$ films are affected by biasing, which allows for tuning the electrical, structural and optical properties of the films. In preliminary studies, effects of biasing on other metal oxide systems have been confirmed as well. For $\mathrm{Al}_{2} \mathrm{O}_{3}$ and $\mathrm{Co}_{3} \mathrm{O}_{4}$ thin films deposited by plasma-assisted ALD, for example, we found that the GPC and the oxide-to-metal ratio were affected by substrate biasing. According to Takagi, changes in material properties generally obtained by increasing the substrate temperature can also be expected when the sample is subjected to energetic ions instead. ${ }^{4}$ Physical mechanisms that might be activated or enhanced by the energetic ions include lattice atom displacement and subsurface implantation. ${ }^{4,9,16}$ Since rutile $\mathrm{TiO}_{2}$ is usually obtained at elevated substrate temperatures or after post-deposition annealing, substrate biasing might replace the need higher thermal processing loads. Another mechanism that might play a role is film stress induced by the physical impact of the energetic ions, which can result in a phase-transformation to a more thermally stable phase. The mechanisms behind the tunability of the material properties by substrate biasing will however need to be addressed in future studies. In order to obtain thin films with preferred material properties, the distribution of the ion energy can also expected to be important. When substrate-tuned biasing or RF biasing is employed, the ion energy can be distributed broadly around the average value of the ion energy. Consequently, for a given bimodal ion energy distribution, the ions with the lower energies might afford beneficial effects, whereas those with higher energies could induce unwanted effects at the same time. With a better defined ion energy, the effects of biasing on thin film material properties might be more selective and more accurately controllable. A narrow distribution of the ion energy can, for example, be obtained by pulsed biasing - a method that uses a more complex bias signal applied to the substrate stage. ${ }^{17}$ Finally, it is noted that the timing of substrate biasing can also be varied within the plasma pulse during ALD. For instance, the substrate biasing can be enabled only after the ALD surface reactions have taken place (typically after the initial second) such that the exposure to high energy ions can be considered an in-situ film treatment executed every ALD cycle.

\section{Acknowledgment}

Dr. T. Fernández Landaluce, W. Keuning, M. J. F. van de Sande, J. J. L. M. Meulendijks, J. J. A. Zeebregts (all TU/e), and Dr. W. M. Arnold Bik (AccTec B.V.) are acknowledged for their assistance. SAFC Hitech Ltd. is thanked for supplying the precursor. This work is carried out within the Thin Film Nanomanufacturing (TFN) programme and is supported financially by the Dutch Technology Foundation STW.

1. H. B. Profijt, S. E. Potts, M. C. M. van de Sanden, and W. M. M. Kessels, J. Vac. Sci. Technol. A, 29, 050801 (2011).

2. E. A. Edelberg, A. Perry, N. Benjamin, and E. S. Aydil, J. Vac. Sci. Technol. A, 17, 506 (1999).

3. H. B. Profijt, P. Kudlacek, M. C. M. van de Sanden, and W. M. M. Kessels, J. Electrochem. Soc., 158, G88 (2011)

4. T. Takagi, J. Vac. Sci. Technol. A., 2, 382 (1984).

5. A. H. M. Smets, W. M. M. Kessels, and M. C. M. van de Sanden, J. Appl. Phys., 102, 073523 (2007).

6. N. Kosku, H. Murakami, S. Higashi, and S. Miyazaki, Appl. Surf. Sci., 244, 39 (2009).

7. Y. H. Lee, Vacuum, 51, 503 (1998).

8. W. Zhou, X. Zhong, X. Wu, L. Yuan, W. Shu, W. Li, and Y. Xia, J. Phys. D: Appl. Phys., 40, 219 (2007).

9. L. M. Williams, and D. W. Hess, J. Vac. Sci. Technol. A, 1, 1810 (1983)

10. T. Hiramatsu, M. Furuta, H. Furuta, T. Matsuda, C. Li, and T. Hirao, J. Cryst. Growth, 311, 282 (2011)

11. J. S. Logan, IBM J. Res. Dev., 14, 172 (1970).

12. D. Gahan, B. Dolinaj, and M. B. Hopkins, Rev. Sci. Instrum., 79, 033502 (2008).

13. A. Sarkar, S. E. Potts, S. A. Rushworth, F. Roozeboom, M. C. M. van de Sanden, and W. M. M. Kessels, ECS Trans. 33, 385 (2011).

14. J. Aarik, A. Aidla, V. Sammelselg, H. Siimon, and T. Uustar, J. Cryst. Growth, 169 496 (1996).

15. S. K. Kim, W.-D. Kim, K.-M. Kim, C. S. Hwang, and J. Jeong, Appl. Phys. Lett., 85, $4112(2004)$

16. Y. Lifshitz, S. R. Kasi, and J. W. Rabalais, Phys. Rev. B, 41, 10468 (1990)

17. P. Kudlacek, R. F. Rumphorst, and M. C. M. van de Sanden, J. Appl. Phys., 106, 073303 (2009). 